\title{
The Future of Work: What is the Impact on Engineering Technicians
}

\section{Dr. Marilyn Barger, Florida Advanced Technological Education Center, FLATE}

Dr. Marilyn Barger is the Principal Investigator and Executive Director of FLATE, the Florida Regional Center of Excellence for Advanced Technological Education, funded by the National Science Foundation and housed at Hillsborough Community College in Tampa, Florida since 2004. FLATE serves the state of Florida as its region and is involved in outreach and recruitment of students into technical career pathways; has produced award winning curriculum design and reform for secondary and post-secondary Career and Technical Education programs; and provides a variety of professional development for SETM and technology secondary and post-secondary educators focused on advanced technologies. She earned a B.A. in Chemistry at Agnes Scott College and both a B.S. in Engineering Science and a Ph.D. in Civil Engineering (Environmental) from the University of South Florida, where her research focused on membrane separation science and technologies for water purification. She has over 20 years of experience in developing curricula for engineering and engineering technology for elementary, middle, high school, and post secondary institutions, including colleges of engineering. Dr. Barger has presented at many national conferences including American Association of Engineering Education, National Career Pathways Network, High Impact Technology Exchange, ACTE Vision, League of Innovation and others. Dr. Barger serves on several national panels and advisory boards for technical programs, curriculum and workforce initiatives, including the National Association of Manufacturers Educators' Council. She is a Fellow of the American Society of Engineering Education, a member of Tau Beta Pi and Epsilon Pi Tau honor societies. She is a charter member of both the National Academy and the University of South Florida's Academy of Inventors. Dr. Barger holds a licensed patent and is a licensed Professional Engineer in Florida.

\section{Dr. Richard Gilbert, University of South Florida}

Richard Gilbert is a Professor of Chemical and Biomedical Engineering at the University of South Florida's College of Engineering . Richard is a Co-PI of a NSF project, DUE 1839567, (ATE 2.0 Preparing Technicians for the Future of Work), supported by the Advanced Technological Education Program. Richard is also the Co-PI for the grant that supports the NSF designated Center of Excellence for Advanced Technological Education in Florida, FLATE. FLATE, now in its 15 year of operation, addresses curriculum, professional development, and outreach issues to support the creation of Florida's technical workforce. Richard has over 30 years of experience working with the K-14 education community. Other funded efforts include projects for the NIH and the US Department of Education. The latter was for the development of an engineering curriculum for elementary school applications. The former is for development of electric field mediated drug and gene applicators and protocols. This effort has generated over 25 patents as well as licensed cancer treatment protocols that have completed Phase II trials. 


\section{Future of Work: How will it Impact Two Year Engineering Technology Programs?}

Introduction

The National Science Foundation (NSF) through its "The Future of Work at the HumanTechnology Frontier" (one of NSF's current 10 Big Ideas) Research Agenda topic is investing resources to determine the impact that new technology in the workspace has on the preparation of the future workforce to be involved with those technologies. From a STEM (science, technology engineering and mathematics) perspective, NSF appreciates that technical workforce education from the preparation of Ph.D. scientists and engineers through the development of skilled technicians will be impacted by new technology's immersion into the workspace. One of these NSF projects, DUE 1839567, (ATE 2.0 Preparing Technicians for the Future of Work) supported by the Advanced Technological Education program is focused on program, curriculum, and course content alterations to assure the creation of technicians that will meet the demands of this new work environment in the advanced technologies.

Skilled technician preparation in the United States today is a broadband system that creates a workforce with the expected characteristics specific to the technology to be serviced. Classically, these technicians are characterized by overarching labels (hydraulics, pneumatics, electronics, mechanics, computer technology) that reflect previous waves of new technology flooding the workplace. These skill sets are still required of tomorrow's technician with the addition insertion of the "digital" age contributions (data knowledge and analysis, advanced digital literacy, and to some extent related business knowledge and processes). This infusion has or will drastically reduce the number of technician programs that just focus on one of the classic skills. Separate technicians with pneumatics or computer technology skills, for example, will not optimally or perhaps even effectively meet the challenges new technology inserts into their "job" expectations.

The two-year engineering technology degree is an existing vehicle used to prepare technicians that service various manufacturing sectors. This educational structure supports industrial positions with multiple titles like maintenance technician, automation technician, and mechatronics technician, etc. in various parts of the United States. The target industries expect a mixed skill set reflective of the overarching disciplines listed above. The skill balance within this mix taught in these programs is usually driven by the major industry sector the college serves. This localized delivery strategy may be essential to satisfy targeted region needs but not a good policy if, as is the case today, the new wave of technology spans all the region's industry sectors. Since it is never a good idea to "through the baby out with the bath water" the challenge is to revise and update engineering technology two-year programs with the adjustments required to meet industries' new Future of Work-related technical demands. 
This presentation will explore the emerging changes in engineering technology (ET) content and education practices to bring new technicians into this Work of the Future evolving workspace. The STEM (technical) skills affected by data knowledge and analysis, advanced digital literacy, as well as process and business operation knowledge, will provide three focus areas. This includes emerging results of a current NSF grant, DUE 1839567, that is probing industry and educators for details about new technologies coming into industries. How are they now and will be dealing with the many workforce issues arising from the introduction of new technologies at this current record pace?

\section{Engineering Technology Education}

Two-year associate degrees in Engineering Technology, ET, will be significantly impacted by Future of Work issues that are arising rapidly. The question is how? Typically, ET degree programs focus on the demands of industries within the 2-year college's service area. This is to be expected and is a valuable element of an ET associate degree program. Another prominent characteristic is that these programs provide pathway options for completing the B.S. Engineering Technology degree typically at engineering colleges within the same region. However, it is also important that the ET degree curriculum provides students with essential knowledge and skills that address the nation's need and interest.

This requirement to have ET programs cognizant of national priorities is very relevant to United States industry today because the rapid inclusion of new technologies into the workplace is directly impacting industry performance and product quality. Additionally, if production industries are not themselves global in nature, most today have a global market. The robotic and automated nature of complex manufacturing environments, Industry 4.0, virtual realities, smart sensors, digital twins, artificial intelligence, and edge computing are just some of the examples of new technology disrupting the entire technical workplace of engineers and technicians. Implicit impacts include the increased need for secure digital communication, large data set analyses, and business connected quality and lean practices to assure profitable operations. A brief digression to look at one example, the communication complications, should accent this point.

\section{Example Implementation of a Future of Work Skill for Technician Education}

Layer 2 protocol (link-layer) communications represent the critical path element in the public and industrial realms. The interconnection of nodes (host, routers, switches and $\mathrm{WiFi}$ ) through individual links in the end to end path is fundamental for information mobility. For specific information, the datagram is "encapsulated" as a link-layer frame with that frame transferred into a target link.

This specific example, condensed to the previous three sentence paragraph, accents technician education issues. First, it is not clear that the language used to state the example is uniform across the computer networking community. Second, it is not clear what the roles of the 4-year and 2-year professional technologists, engineers and technicians are. Finally, even if it is agreed that technician comfort with the Ethernet as the link between an access point and a link-layer switch, between the link-layer switch and the router, between the two routers, between the 
second router and its target link-layer switch, and finally between that switch and a target server is essential, does that mean the same technician is involved in the complete datagram transport?

At this point in time, industry wants to use technician resources instead of its engineering resources to deal with Industry 4.0 innovations. This brings us back to the 2 -year engineering technology education pathway and, indirectly, this specific example situation. Most manufacturers will not depend on ISPs (Internet Service Providers) to deal with in-house critical path process communication problems. Only major industry players will invest in fulltime dedicated technicians to deal with communication problems. Smaller companies will have their current multi-disciplined technician become the "work horse" in this technology as well. Thus, the need to keep the 2-year ET degree enterprise vibrant.

Depth and breadth issues are always the challenge for 2-year ET degree programs. In this case, the simple solution (add a course in "communication protocols and technologies") to the program, is not practical for two reasons. First, such a course has much more information than the technician needs. Second, there is no "credit space" available in these programs. The second point is specifically important since the national trend is to reduce existing programs to fit under a 60 -credit hour ceiling.

The Florida Department of Education (FLDOE) in partnership with the National Science Foundation Advanced Technological Education (NSF-ATE) Center of Excellence for Manufacturing Education in Florida, FLATE (DUE 1204751), has addressed both the content and credit hour criteria for the A.S. Engineering Technology Degree program offered in 24 state colleges in Florida. The following two figures illustrate its design and structure. Table 1 presents an example of the ET degree program with a specialization in Advanced Manufacturing as executed at one of these colleges, the College of Central Florida, in Ocala, Florida.

The first diagram presents the degree design characteristics. The diagram depicts two major entry pathways with access avenues to those pathways. The horizonal entrance arrow indicates the two traditional ways (GED and a general High School graduate) to enter A.S. degree programs in Florida. The alternative approach (arrow from the top) accents admission by alternative pathways different from the high school options, a FLDOE supported high school academy or technical program, as well as apprenticeship, workforce (industry recognized credentials), and technical schools. In all cases, the entry level student course of study will focus on the

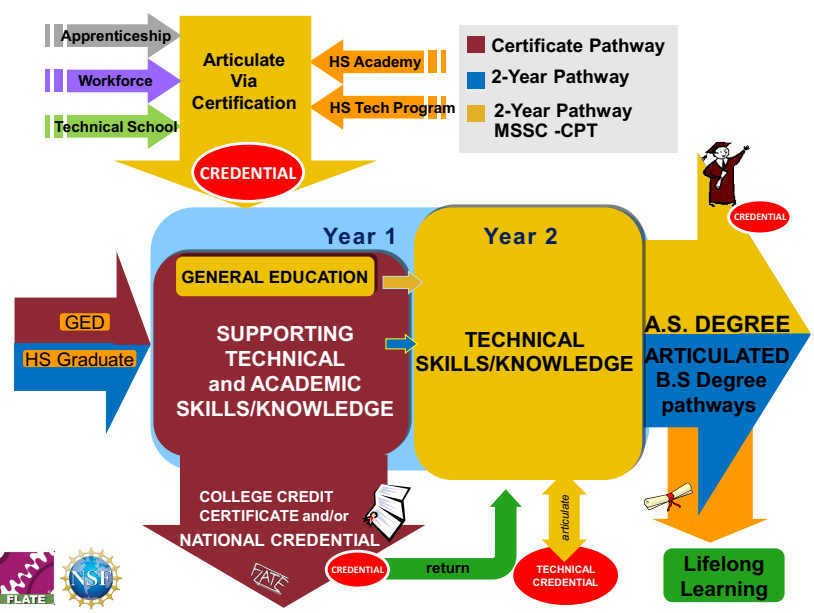
college's general education requirements (15 credits) and the ET degree first-year core supporting technical knowledge and skill courses. Year 2 of the program is directed to the knowledge and skill expectations possessed by technicians in specific specialized fields. This $30-$ credit collection (including technical electives that support college certificates and national credentials) of education experiences includes classroom and hands-on education and training, as 
well as for some programs supervised industry experience. The exit arrow on the right highlights the associate degree graduate options that include direct employment opportunities in the chosen degree specialization and articulation into appropriate B.S. programs available in Florida. These include B.S. Engineering Technology for continued study in technical engineering disciplines and B.A.S. (Bachelor of Applied Science) Technology Management, Supervision and Leadership, and other non-technical pathways.

The second diagram fills in the course of study options in more detail. The general education requirements are not specified since they very slightly from college to college. There are no surprises in the course subject areas students take to meet these requirements, but the hours required and allowed transfer course are subject to individual college rules and guidelines. Although the core first year E.T. degree course requirements are not as college flexible there are degrees of freedom in what is presented in these courses. These six course areas (Computer Aided Design, Introduction to Electronics, Manufacturing Materials \& Processes, Mechanical

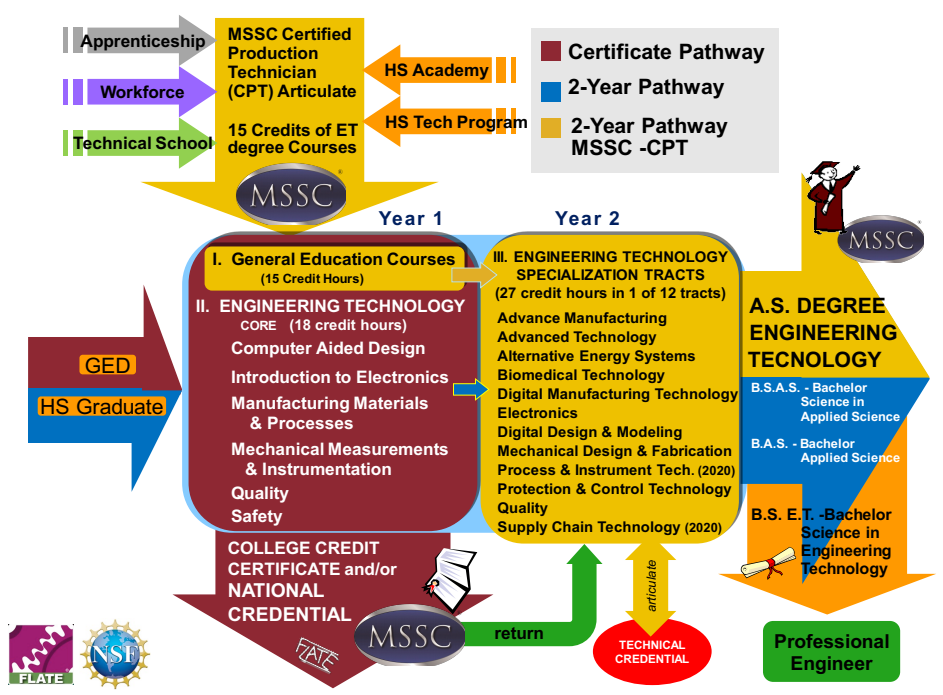
Measurements \& Instrumentation, Quality, and Safety) are competency-based courses with Standards and Benchmarks monitored, maintained, and updated regularly by the FLDOE. The specifics of these criteria are established by industry and faculty consensus across the State with compulsory FLDOE conducted industry review every three years.

The specifics of the Engineering Technology Associate in Science degree program at College of Central Florida (CF) located in Ocala, Florida will accent how the statewide degree is implemented at a specific college. In addition to the degree, CF offers College Credit Certificates (CCC's) and industry-based credentials. The available CCC's include Automation (12 credit hours), Engineering Technology Support Specialist (18 credit hours), Lean Six Sigma Green Belt (12 hours), Mechatronics (18 credit hours), Pneumatics, Hydraulics and Motors for Manufacturing (12 credit hours), and Mechanical Designer and Programmer (12 credit hours). These certificates are recognized as knowledge and skill level competencies by regional industry with credit transfer options to the other colleges in Florida offering the A.S. ET degree. Completion of courses within these CCC's will allow students to be eligible to sit for nationally recognized certificates such as the MSSC-CPT (Manufacturing Skills Standard Council-Certified Production Technician), Lean Manufacturing Bronze Certification, and Fanuc's Certified Robotics training. The courses related to credentials reside in the first and second year of the CF program. With this ET associate degree design and structure in place, options that address a Future of Work issue, in this case the Layer 2 protocol (link-layer) communications challenge, can be readily formulated. 
Table 1: College of Central Florida A.S. ET with Advanced Manufacturing Specialization Technical Courses

\begin{tabular}{|l|l|}
\hline $\mathbf{1}^{\text {st }}$ Year & Core Courses \\
\hline CGS 1100 & Microcomputer Applications \\
\hline EET 1084 & Survey of Electronics \\
\hline EGN 1111 & Engineering Graphics \\
\hline ETI 1117 & Introduction to Quality Control \\
\hline ETI 1411 & Manufacturing Processes I \\
\hline ETI 1151 & Instrument Techniques and Measurement \\
\hline ETI 1720C & Industrial Safety \\
\hline $2^{\text {nd }}$ Year & Specialization Courses (Advanced Manufacturing) \\
\hline ETI 1843 & Motors and Controls \\
\hline ETM 2401 & Mechanical Devices and Systems \\
\hline ETS 1535 & Automation Process Control \\
\hline ETS 1540 & Industrial Applications Using PLCs and Robotics \\
\hline ETS 1542 & Introduction to PLCs \\
\hline ETS 1700 & Hydraulics and Pneumatics \\
\hline
\end{tabular}

For this presentation a "cut to the chase" discussion of the example is adopted. Industry applications will not use the UDP, User Datagram Protocol, (the no-frills, low reliability option). The technician will deal with the TCP transport protocol and a protocol standard, RFC for example, with the "open" applications to be dealt with precisely defined in RFC 2616. This assumption is, of course, that all the developers writing code for the application are on the same page and follow the same rules. When the application is associate with a proprietary network, the specifics are probably related to RFC practices without the "follow those rules" expectation.

In either the open or proprietary situations, the technician will have to have a comfort level with a language within the communications field. Code written in Java, C, C++ and Python are used with Python a current favorite. (Python usually requires fewer lines of code and each line can be explained to an inexperienced programmer without difficulty.) Disregarding developer preference, it is not necessary that a technician master several languages. One of the needed languages will already be taught in CGS 1100. With a good grasp of that language in place, additional language knowledge and skill sets should initially be focused on the input/output (I/O) and $\mathrm{read} / \mathrm{write}(\mathrm{R} / \mathrm{W})$ properties of the other languages. For this example, an RFC protocol with a well-known port number means the technician must recognize how that port address interacts with the code they are examining. These additional learning objectives can be developed and shaped as lessons and projects that complement and expand student work in CGS 1100 and other more advanced and equipment specific Engineering Technology A.S. degree courses like ETS 1535, ETS 1540 and/or ETS 1542.

One example of using a complementary learning opportunity would be to insert these focused protocol lessons as components of ETS 1540 and ETS 1542. These courses already expose students to communications practices used in programmable Logic controllers (PLC) that oversee the synchronous and asynchronous operation of multiple equipment subsets. Granted, 
PLC overall control of a system may be via a proprietary network (the Fanuc robots used in ETS 1540), however, technicians working with this robot-controlled equipment will have limited but focused access to Fanuc's network code. In those situations, technicians will be working within a "semi open" open environment that will follow coding practices they are familiar with.

Summary and Future Work

The introduction of new technology into the workplace always generates ripples throughout the technical workforce supporting that workplace. The "Preparing Technicians for the Future of Work" NSF ATE project, DUE 1839567, has categorized some topics that educators around the country have identified as possibly skills that advanced technology A.S. programs will need to address no matter which industry sector they respond to. Table 2 presents the most frequent responses from data gathered at focused workshops, site visits, and targeted surveys. To optimize this NSF ATE project outcomes for enhancing 2-year technician education, the categorized list is being reviewed by subject matter experts. The experts will provide guidance to make the list as usable and relevant as possible by removing redundant items, identify the best vocabulary to use, and modifying and/or eliminate topics not appropriate for 2-year technician education.

Table 2. Categorized Unprioritized Responses to Future of Work Topics for ET Technician Education

\begin{tabular}{|l|l|l|l|}
\hline DATA KNOWLEDGE & \multicolumn{1}{|c|}{$\begin{array}{l}\text { ADVANCED DIGITAL } \\
\text { LITERACY ANALYSIS }\end{array}$} & $\begin{array}{c}\text { BUSINESS KNOWLEDGE } \\
\text { \& PROCESSES }\end{array}$ \\
\hline 1. & Applied math & 5G & Agility \\
\hline 2. & Basic programming & Additive mfg software & Blockchain \\
\hline 3. & College algebra & AI software tools & Business \& economics fluency \\
\hline 4. & Communication & Automation/robotics & Business cycles \\
\hline 5. & Computational thinking & Business continuity & Communication \\
\hline 6. & Data analysis & Cloud computing & Company's "brand" \\
\hline 7. & Data backup and restoration & College algebra & Confidentiality \\
\hline 8. & Data ethics & Communication & Continuous improvement \\
\hline 9. & Data flow: origin to end user & Controls & Decision making \\
\hline 10. & Data fluency/vocabulary & Cyber-physical systems & Entrepreneurship \\
\hline 11. & Data management \& storage & Digital fluency/vocabulary & Ethics \\
\hline 12. & Data modeling & Digital twins & Internal/external customer focus \\
\hline 13. & Documentation & Edge computing & Lean processes \\
\hline 14. & Excel/spreadsheets & Function blocks & Market trends \\
\hline 15. & Gap analysis & Human Machine Interfaces & Problem solving \\
\hline 16. & Linear algebra & Internet of Things & Production / supply chains \\
\hline 17. & Machine learning & Machine learning & Quality control \\
\hline 18. & PLCs & Microsoft Office tools & Risk management \\
\hline 19. & Predictive maintenance & Network architecture & ROI \\
\hline 20. & Querying language & Network communication & Role awareness in company \\
\hline 21. & Business analytics software & PLCs & Six Sigma \\
\hline 22. & Sensors & Python, basic programming & Supply/demand \\
\hline 23. & SQL/databases & Risk management & Sustainability \\
\hline & & & \\
\hline
\end{tabular}




\begin{tabular}{|l|l|l|l|}
\hline 24. & Statistics & Security & Value-added chain \\
\hline 25. & Data visual representation & Troubleshooting & Vertical \& horizontal integration \\
\hline
\end{tabular}

From an education vehicle perspective, for technicians that need skills that cross technologies, the two-year engineering technology program can provide the flexibility to address national and regional Future of Work issues generated by specific new technology subsets that affect the industries in the college's sphere of influence. The statewide A.S. Engineering Technology developed by FLATE (the NSF-ATE Advanced Technological Education Center for Manufacturing Education in Florida) and implemented through the Florida Department of Education is a model example of how Future of Work skill and knowledge challenges are being addressed. This model provides the rigor with regular It also has statewide industry appeal for its breath of instruction as well as accessibility across the state. Additionally, the degree plan maintains the flexibility for faculty to address Future of Work generated skill deficiencies as identified by their program's industry partners. 